\title{
In-vitro-in-silico investigation of the negative food effect of zolpidem when administered as immediate-release tablets
}

\author{
Rafael Leal Monteiro Paraiso ${ }^{\mathrm{a}}$ (D), Ayahisa Watanabe ${ }^{\mathrm{b}}$, Cord J. Andreas ${ }^{\mathrm{a} \dagger}$, David Turner $^{\mathrm{c}}$, \\ Patricia Zane $^{d}$ and Jennifer Dressman ${ }^{a}$

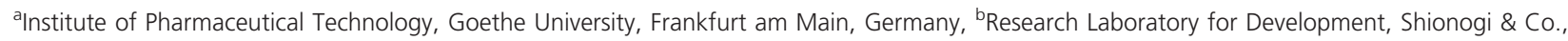 \\ Ltd., Osaka, Japan, 'Simcyp Division, Certara UK Limited, Sheffield, UK, dDrug Disposition, Safety, and Animal Research (DSAR), Sanofi U.S., \\ Bridgewater, NJ, USA
}

\section{Keywords}

biorelevant dissolution; food effect; in-vitroin-vivo correlation; PBPK modelling; zolpidem

\section{Correspondence}

Jennifer Dressman, Institute of Pharmaceutical Technology, Goethe University Frankfurt, Max von Laue St. 9, 60438 Frankfurt am Main, Germany. E-mail: dressman@em.uni-frankfurt.de

Received June 21, 2019

Accepted August 10, 2019

doi: 10.1111/jphp.13161

†Present Address: Sanofi-Aventis Deutschland GmbH, Industriepark Höchst, K703, Frankfurt, Germany

Rafael Leal Monteiro Paraiso and Ayahisa Watanabe are equal first authors.

\begin{abstract}
Objectives The main objective of the present work was to combine in vitro and in silico tools to better understand the in vivo behavior of the immediate release (IR) formulation of zolpidem in the fasted and fed states.

Methods The dissolution of zolpidem was evaluated using biorelevant media simulating the gastric and intestinal environment in the fasted and fed states. Additionally, the influence of high viscosity and high fat content on the release of zolpidem under fed state conditions was investigated. The in vitro results were combined with a physiologically based pharmacokinetic (PBPK) model constructed with Simcyp ${ }^{\circledR}$ to simulate the zolpidem pharmacokinetic profile in both prandial states.

Key findings In vitro biorelevant dissolution experiments representing the fasted and fed states, combined with PBPK modelling, were able to simulate the plasma profiles from the clinical food effect studies well. Experiments reflecting the $\mathrm{pH}$ and fat content of the meal led to a good prediction of the zolpidem plasma profile in the fed state, whereas increasing the viscosity of the gastric media led to an under-prediction. Conclusions This work demonstrates that the combination of biorelevant dissolution testing and PBPK modelling is very useful for understanding the in-vivo behavior of zolpidem in the fasted and fed states. This approach could be implemented in the development of other drugs exhibiting negative food effects, saving resources and bringing new drug products to the market faster.
\end{abstract}

\section{Introduction}

The influence of food intake on the pharmacokinetics of drugs is of clinical importance because interactions between food and the drug can lead to changes in the plasma profile and subsequently in the therapeutic effect of the drug. In general, food can have a positive effect (higher plasma levels), negative effect (lower or later plasma levels) or no significant effect on drug absorption.

In some cases, because of the poor absorption of some drugs, a positive food effect is necessary for the drug to achieve a therapeutic effect. In other cases, a positive food effect may increase the risk of drug toxicity, especially if the drug has a narrow therapeutic index. On the other hand, a negative food effect may increase the risk of treatment failure, due to insufficient concentration at the site of action. ${ }^{[1]}$
One well-known category of food-drug interactions involves inhibition of the cytochrome P450 enzymes that are responsible for the metabolism of drugs, resulting in an increase in the systemic exposure of the drug administered. ${ }^{[2,3]}$ But there are several other categories of fooddrug interactions. ${ }^{[1,4-6]}$ For example, ingestion of food prolongs the gastric emptying time and increases blood flow to the gut, which can lead to a slower absorption rate or more efficient absorption of the drug, respectively. Other food effects are mediated physicochemically, for example the increase in gastric $\mathrm{pH}$ induced by food ingestion may change the rate of release of drug from the dosage form. ${ }^{[7]}$ Likewise, enhancement of the solubility of the drug as a result of increased bile secretion in response to meal intake may lead to improved absorption for a poorly soluble, lipophilic drug. Further examples include the impact of 
increased luminal viscosity on disintegration of the dosage form, complexation of the drug with food components or catalysis of drug degradation by food components, all of which can lead to a reduction in the amount of drug available for absorption. ${ }^{[8]}$

Some recent studies have addressed the specific physiological changes that may lead to food effects. A quantitative meta-analysis performed by Abuhelwa et al., ${ }^{[9]}$ examining data in healthy volunteers from the open literature, found that the increase in and variability of gastric $\mathrm{pH}$ are significantly influenced by the caloric content of the meal ingested. An increase in the $\mathrm{pH}$ value in the stomach will have an impact on drugs that are weakly acidic (increasing the solubility) or weakly basic (decreasing the solubility) in the gastric environment. ${ }^{[10]}$ Other studies have indicated that there can be an inverse relationship between the increase in viscosity after food intake and drug absorption. An increase in viscosity can result in a decrease in drug diffusivity, slowing release of the drug into the gastric contents und potentially decreasing the rate of drug absorption. ${ }^{[8,11]}$

The biopharmaceutical classification system (BCS) proposed by Amidon et al. in 1995 has been used to predict the type of food effect that can be expected for the different classes of drugs. Generally, for drugs that belong to BCS class I, which exhibit high solubility and high permeability, food intake is not expected to elicit changes in the extent of absorption. ${ }^{[1]}$ Nevertheless, for some drugs that belong to this class, food effect studies have demonstrated a lower peak concentration $\left(C_{\max }\right)$ of the drug, reflecting a decrease in the absorption rate, or reduced absorption. ${ }^{[12-16]}$

According to the BCS, zolpidem is considered to be a class I drug ${ }^{[17]}$. For medications used to treat anxiety or sleep disorders, such as zolpidem, a rapid onset of action is highly desirable. ${ }^{[18]}$ As food intake is usually associated with slower gastric emptying, drug absorption can be delayed or even decreased when compared with administration in the fasted state. Therefore, it has been suggested that co-administration with a standard high-viscosity, high-fat meal could retard the rate of absorption of zolpidem and may also lead to a reduction of the extent of absorption. ${ }^{[15,16]}$

Twenty years ago, Welling opined that it is often difficult to predict whether co-administration of food will increase, decrease or have no effect on the rate and extent of drug absorption, since food-drug interactions can be either predominantly drug substance or drug formulation related. ${ }^{[19]}$ However, more recent studies have supported the use of dissolution in biorelevant media coupled with physiologically based pharmacokinetic (PBPK) models to simulate the effect of food intake on the pharmacokinetic profile. In this approach, the physicochemical properties of the drug together with biorelevant dissolution data and physiological parameters are combined with $\mathrm{PBPK}$ modelling to predict the plasma profile of the drug. ${ }^{[16,20,21]}$
The main objective of the present work was to use in-vitro and in-silico tools to better understand the in-vivo behaviour of the immediate-release (IR) formulation of zolpidem. First, a PBPK model for zolpidem was established. Then, the dissolution behaviour of immediate-release zolpidem formulations in biorelevant media simulating the fasting and fed states was integrated into the model. Based on the in-vitro biorelevant dissolution results, the in-vivo plasma profiles were simulated using a PBPK model built in Simcyp ${ }^{\circledR}$ using a 'middle-out' approach and compared with those observed in in-vivo studies. ${ }^{[22]}$ Finally, the relative influence of $\mathrm{pH}$ elevation, high-fat content and high viscosity in the stomach environment on zolpidem plasma levels was evaluated by modifying the conditions of the in-vitro testing appropriately.

\section{Materials and Methods}

\section{Materials}

Zolpidem active pharmaceutical ingredient (API) and $10 \mathrm{mg}$ immediate-release (Stilnox ${ }^{\circledR}$; Sanofi-Aventis, Gentilly, France) film-coated tablets were obtained commercially (Lot \#70662). FaSSIF, FeSSIF \& FaSSGF Powder (Lot \#01-1512-05-NP) and FaSSIF-V2 Powder (Lot no. 03-161002) were kindly donated by biorelevant.com (Surrey, UK). Glyceryl monooleate (GMO) was also donated to the Goethe University by biorelevant.com. Lipofundin MCT 20\% was purchased from B. Braun (Melsungen, Germany). Methylhydroxypropylcellulose (HPMC, Hypromellosum E4M Prem) was purchased from Fagron $\mathrm{GmbH}$ \& Co. KG (Barsbüttel, Germany). Maleic acid, sodium dihydrogen phosphate dihydrate, dodecyl sulphate sodium, acetonitrile and methanol HPLC grade were obtained from Merck KGaA (Darmstadt, Germany), while sodium acetate trihydrate, sodium chloride, potassium dihydrogen phosphate, sodium hydroxide, disodium hydrogen phosphate dodecahydrate, tris-(hydroxymethyl) aminomethane, $\mathrm{D}(+)$-glucose, acetic acid $100 \%$, hydrochloric acid 37\%, hydrochloric acid $1 \mathrm{~N}$, orthophosphoric acid $85 \%$ and sodium hydroxide $1 \mathrm{~N}$ were purchased from VWR (Leuven, Belgium) and were of analytical grade. Sodium oleate (N 82\% fatty acids) was obtained from Sigma-Aldrich (Steinheim, Germany).

\section{In-vivo studies}

The influence of food on the pharmacokinetics of zolpidem was investigated in 30 healthy, male volunteers under fasting and fed state conditions in a study conducted by Sanofi-Aventis. The study protocol, the mean pharmacokinetic profiles and the summary statistics for the pharmacokinetics were kindly provided by Sanofi-Aventis. The study was conducted in an open-label, $2 \times 2$ crossover study design with a washout period of 1 week. The patients 
received a zolpidem $\left(\right.$ Stilnox $\left.{ }^{\circledR}\right) 10 \mathrm{mg}$ immediate-release tablet ingested together with $240 \mathrm{ml}$ of water either in the fasted state or $20 \mathrm{~min}$ after consuming an evening meal, which consisted of a roast beef sandwich on whole wheat bread, a banana and skim milk. The tablets were administered at 10 p.m. and, because of the hypnotic effect of the drug, the patients were asked to assume a supine position in preparation for sleep and remain so until the following day at 10 a.m. The pharmacokinetic profile of zolpidem was determined by collecting blood samples at pre-dose, $0.25,0.5,0.75,1,1.25,1.5,2,3,4,5,6,8,10$ and 12 h postdose.

The clinical study was performed in accordance with good clinical practices and the Declaration of Helsinki. Although the summary pharmacokinetic parameters for this study have been previously been published, the mean plasma profiles have not (data on file at Sanofi-Aventis).

\section{Biorelevant dissolution tests}

The compositions of the media used for this work to simulate the fasted and fed states are summarized in Tables 1, 2 and 3 , respectively. To better simulate the gastrointestinal environment, the Level II biorelevant media contain bile components, dietary lipids and lipid digestion products, as well as osmolality-adjusting agents. ${ }^{[23]}$ In Table 1 , the Level II dissolution media used to simulate the gastric environment in different periods after food ingestion, that is FeSSGF $_{\text {early }}$ (representing the gastric environment in the first 75 min after ingestion of the meal), FeSSGF middle (75$165 \mathrm{~min}), \mathrm{FeSSGF}_{\text {late }}(165 \mathrm{~min}$ and longer after meal ingestion), as well as FeSSIF-V2, simulating the upper intestine in the fed state, are described. The dissolution media simulating fasted and fed state were prepared according to previously published procedures. ${ }^{[23]}$

Biorelevant dissolution tests were performed using calibrated USP 2 dissolution test apparatus (Erweka DT 80, Erweka $\mathrm{GmbH}$, Heusenstamm, Germany) at $37 \pm 0.5^{\circ} \mathrm{C}$ in $500 \mathrm{ml}$ of each medium. To simulate the fasted state, release was investigated at $50 \mathrm{rpm}$, while the fed state testing (see media in Table 1) was conducted at $75 \mathrm{rpm}$.

The experimental conditions used to evaluate the effect of fat content and viscosity on release are shown in Tables 2 and 3, respectively. Sampling for all dissolution tests was performed at 5, 10, 20, 30, 40, 50, 60, 120 and $180 \mathrm{~min}$. Additional sampling times of 4 and $6 \mathrm{~h}$ were necessary to determine the extent of release in experiments investigating the effect of viscosity on the release of the drug.

\section{Biorelevant dissolution to investigate the effect of $\mathrm{pH}$ and fat on the release of the drug}

To evaluate the effect of $\mathrm{pH}$ and fat content added in the FeSSGF Level II media on the release profile of zolpidem from the formulation, different percentages of fat were added to the dissolution media, as described in Table 2. In order to simulate the fat content in the stomach after eating, Lipofundin MCT 20, an emulsion used for parenteral nutrition, was used in various proportions of Lipofundin/buffer to represent various periods after meal ingestion. ${ }^{[23]}$ The concentration of the drug in the Lipofundin/buffer samples was determined by filtering the sample through a $1.2-\mu \mathrm{m}$ cellulose acetate syringe filter (Minisart NML; Sartorius, Goettingen, Germany) and centrifuging the filtrate at $18.407 \mathrm{~g}$ for $10 \mathrm{~min} .0 .5 \mathrm{ml}$ of supernatant was then diluted with $1 \mathrm{ml}$ of acetonitrile or methanol before HPLC analysis.

Table 1 Composition and physicochemical characteristics of Level II biorelevant media for simulating the environment of the stomach and the small intestine in the fed state

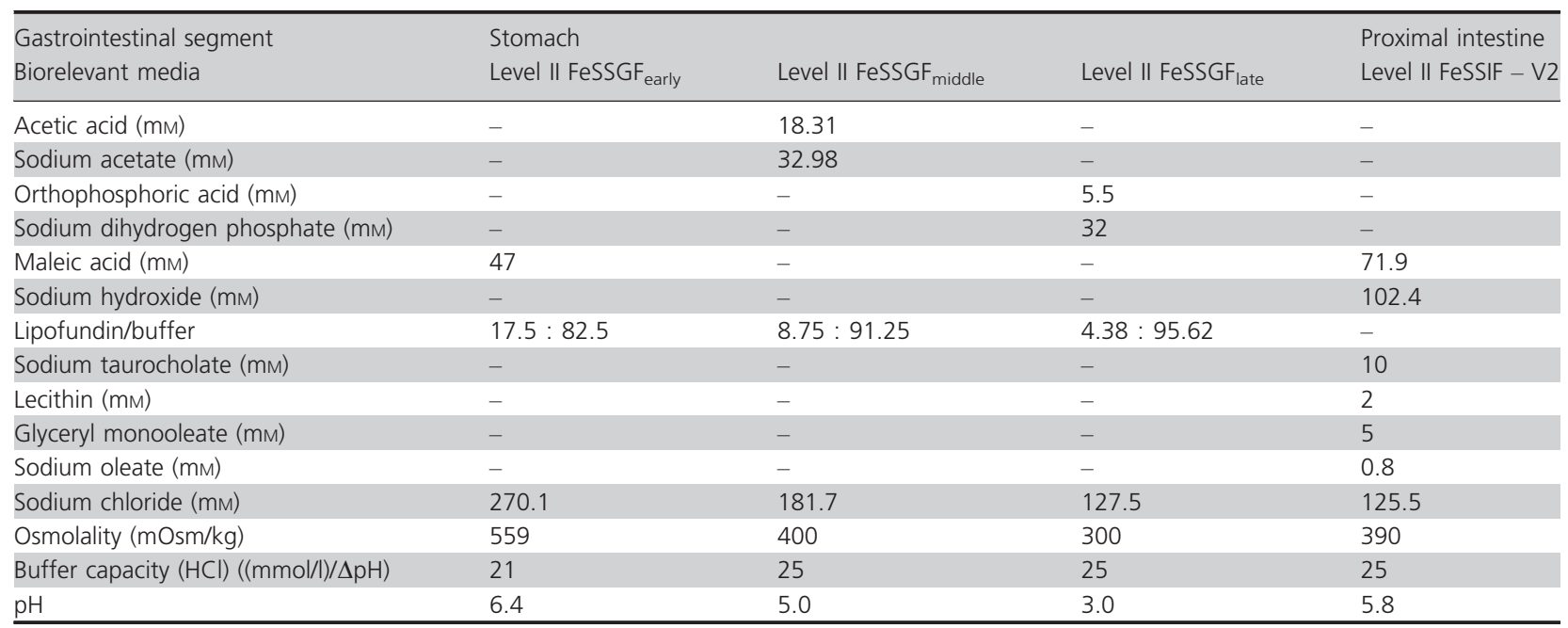


Table 2 Experimental conditions to simulate the effect of $\mathrm{pH}$ and high fat on the release of the drug

\begin{tabular}{llllll}
\hline & $0.88 \%$ fat & $1.75 \%$ fat & $3.5 \%$ fat & $7.5 \%$ fat \\
\hline FeSSGF late $\mathrm{pH} \mathrm{3.0}$ & $\mathrm{x}$ & - & - & $\mathrm{x}$ \\
FeSSGF & & $\mathrm{x}$ & - & $\mathrm{x}$ \\
FeSSGF & $\mathrm{xH} 5.0$ & - & - & $\mathrm{x}$ & $\mathrm{x}$ \\
\hline
\end{tabular}

Table 3 Experimental conditions to simulate the effect of $\mathrm{pH}$ and high viscosity (hydroxypropylmethylcellulose (HPMC)) on the release of the drug

\begin{tabular}{llll}
\hline Percentage of HPMC added to the media (\%) & 0 & 0.5 & 1.4 \\
\hline FeSSGF late $\mathrm{pH} 3.0$ & - & $\mathrm{x}$ & $\mathrm{x}$ \\
FeSSGF & - & $\mathrm{x}$ & $\mathrm{x}$ \\
\hline
\end{tabular}

\section{Biorelevant dissolution to investigate the effect of hydroxypropylmethylcellulose and $\mathrm{pH}$ on the release of the drug}

To evaluate the effect of the increase in viscosity of the gastric contents following ingestion of a meal on the release profile of zolpidem, HPMC was added in two concentrations: $0.5 \%$ with viscosity of $20 \mathrm{cP}$ and $1.4 \%$ viscosity of $120 \mathrm{cP}$ (see Table 3), as suggested by Langguth et al. To prepare the higher viscosity media, the proposed amount of HPMC was dispersed in one-third of the amount of purified water needed for media preparation, preheated to $80^{\circ} \mathrm{C}$ and then, after cooling, sufficient water was added to the HPMC dispersion to make it to volume. ${ }^{[8]}$

To determine the concentration of zolpidem in the dissolution samples, these were filtered through a $0.45-\mu$ MPTFE filter (ReZist 30 syringe filter, Sigma Aldrich Chemie $\mathrm{GmbH}$, Munich, Germany) and subsequently diluted with mobile phase before HPLC analysis.

\section{Analysis of samples}

The samples were prepared as described above, and the concentration of zolpidem was determined by using HPLC (Hitachi Chromaster; Hitachi Ltd., Tokyo, Japan and SpectraSystem, ThermoQuest Inc., San Jose, CA, USA). The analyses were run on a PurospherStar C18, $5 \mu \mathrm{m}$, $150 \times 4.6 \mathrm{~mm}$ column (Merck KGaA). Zolpidem was analysed using a mixture of $60 \%$ acetonitrile, $40 \%$ water and $0.01 \%$ diethylamine as the mobile phase, at a flow rate of $1.5 \mathrm{ml} / \mathrm{min}$. The sample absorbance was measured with a UV detector at a wavelength of $245 \mathrm{~nm}$. The limits of detection (LOD) and quantification (LOQ) were 0.03 and $0.09 \mu \mathrm{g} / \mathrm{ml}$, respectively.

\section{PBPK model}

A PBPK model was built using the Simcyp ${ }^{\circledR}$ Simulator (V17.1; Certara, Sheffield, UK) using the parameters shown in Table 4. Data for the physicochemical and pharmacokinetic properties of zolpidem were obtained from the literature sources cited in Table 4. The advanced dissolution, absorption and metabolism (ADAM) model was used to describe the process of dissolution and absorption. The structure of the ADAM model has already been described in detail in the literature. ${ }^{[24,25]}$

Simulation of the plasma profiles after oral administration of Stilnox ${ }^{\circledR} 10 \mathrm{mg}$ IR tablets was run with a 'middle-out' approach $^{[22]}$ using pharmacokinetic disposition parameters derived from in-vivo data and in-vitro studies (e.g. gut wall permeability, enzyme kinetics and solubility) available in the literature and from dissolution experiments under standard biorelevant conditions. To build the elimination phase in the PBPK model, information about CYP contributions derived from human liver microsomes (HLM) was used to describe the enzymatic clearance of zolpidem. ${ }^{[26,27]}$ All simulations described in this study were carried out using the Simcyp ${ }^{\circledR}$ healthy volunteer population in the fasted or fed state (using default software values, but with an all-male population) and the parameter values described in Table 4. Simulations were performed only for male patients due to the all-male volunteer composition in the clinical study. Before introducing the dissolution data simulating the fasted and fed states into Simcyp ${ }^{\circledR}$ software, they were fitted to a piecewise cubic polynomial interpolation function. The functions used to fit the in-vitro biorelevant dissolution profiles were then used to calculate the in-vivo dissolution in the software for the fasted and fed state, respectively.

\section{Data presentation and statistical analysis}

The dissolution experiments were performed at least in triplicate $(n \geq 3)$, and the data are presented as the arithmetic means with standard deviations. The in-vivo plasma profile data are presented as means, as no statistics on the variability of the plasma concentrations at each sampling point were available in the Sanofi archives. However, the coefficients of variation for the summary pharmacokinetic parameters were located and are reported along with the means. The simulated (predicted) plasma profiles using Simcyp software were compared with in-vivo (observed) profiles using the average fold error (AFE) and absolute average fold error (AAFE) ${ }^{[28,29]}$, whereby the AFE is defined as:

$$
\mathrm{AFE}=10^{\frac{1}{n} \sum i{ }^{\text {predicted }_{i}}}
$$

where $n$ is the number of time points at which the concentration was obtained, and predicted ${ }_{i}$ and observed ${ }_{i}$ are the predicted and observed concentrations at a given time point $i$. The average fold error indicates whether the predicted profile underestimates or overestimates the observed values (as shown in Eq. 1): if the $\mathrm{AFE}<1$, there 
Table 4 Parameters used for the zolpidem PBPK model (Simcyp ${ }^{\circledR}$ Simulator V17)

\begin{tabular}{|c|c|c|}
\hline Parameters & Value & Reference/comments \\
\hline Molecular weight $(\mathrm{g} / \mathrm{mol})$ & 307.39 & Salvà and Costa ${ }^{[56]}$ \\
\hline $\log P$ & 2.42 & Salvà and Costa ${ }^{[56]}$ \\
\hline Compound type & Monoprotic base & Salvà and Costa ${ }^{[56]}$ \\
\hline pKa & 6.16 & Salvà and Costa ${ }^{[56]}$ \\
\hline Absorption & ADAM model & \\
\hline Peff & $6.5 \times 10^{-4} \mathrm{~cm} / \mathrm{s}$ & Andreas et al. ${ }^{[16]}$ \\
\hline Distribution & Minimal PBPK model & \\
\hline Main binding protein & Albumin & Chetty et al. ${ }^{[57]}$ \\
\hline Vss $(1 / \mathrm{kg})$ & 0.68 & Chetty et al. ${ }^{[57]}$ \\
\hline Fu gut & 0.035 & Predicted \\
\hline Blood to plasma coefficient (B : P) & 0.76 & Salvà and Costa ${ }^{[56]}$ \\
\hline Fu plasma & 0.08 & Durand et al. ${ }^{[58]}$ \\
\hline Elimination & Enzyme kinetics & \\
\hline HLMs ( $\mu$ l/min/pmol enzyme) & & Von Moltke et al. ${ }^{[26]}$ \\
\hline Clint CYP 3A4 & 0.217 & Von Moltke et al. ${ }^{[26]}$ \\
\hline Clint CYP 2C9 & 0.147 & Von Moltke et al. ${ }^{[26]}$ \\
\hline Additional Clint & 1.460 & Von Moltke et al. ${ }^{[26]}$ \\
\hline CLR (renal clearance) $(\mathrm{l} / \mathrm{h})$ & 0.18 & \\
\hline Formulation option in the software & $\begin{array}{l}\text { Immediate release (IR) with piecewise cubic polynomial interpolation of } \\
\text { the observed in-vitro dissolution data }\end{array}$ & Default function in Simcyp ${ }^{\circledR}$ \\
\hline Population modelling & $\begin{array}{l}\text { Virtual population trials were conducted using } 300(30 \times 10) \text { male } \\
\text { healthy volunteers, age ranged } 18-45 \text { years for each study }\end{array}$ & FDA approval document \\
\hline Transit times in ADAM & $\begin{array}{l}0.4 \mathrm{~h} \text { for fasted state mean GET and } 1.0 \mathrm{~h} \text { for fed state mean GET with } \\
38 \% \mathrm{CV} \text { for population in both states. Other GI transit times were also } \\
\text { set at the default values }\end{array}$ & Default values in Simcyp ${ }^{\circledR}$ \\
\hline
\end{tabular}

is an underestimation, and if the AFE $>1$, there is an overestimation of the observed value.

The absolute average fold error quantifies the absolute error from the true value (as shown in Eq. 2). If AAFE $\leq 2$, the simulation is usually considered acceptable. ${ }^{[28,29]}$

$$
\mathrm{AAFE}=10^{\frac{1}{n} \sum\left|\log _{\text {observed }_{i}}^{\text {predicti }_{i}}\right|}
$$

\section{Results and Discussion}

\section{In-vivo studies}

Figure 1 shows the average plasma profiles of zolpidem after administration of $10 \mathrm{mg}$ Stilnox ${ }^{\circledR}$ immediate-release tablets in the fasted and fed states in 30 healthy male volunteers. The accompanying summary statistics for the pharmacokinetic study are presented in Table 5. According to the mean profiles obtained, lower values for both AUC and $C_{\max }$ and a $60 \%$ prolongation in time to reach the maximum concentration $\left(T_{\max }\right)$ were observed in the fed state compared with fasted state administration. The fed/fasted ratios for AUC and $C_{\max }$ were 0.86 and 0.76 , respectively, indicating that in the fed state, AUC and $C_{\max }$ were decreased on the average by $\sim 15$ and $25 \%$, respectively, compared with the fasted state.
As can be seen in Figure 1, the shape of the mean plasma profile of Stilnox ${ }^{\circledR} 10 \mathrm{mg}$ differs significantly between the fed and fasted states. As zolpidem belongs to BCS class I (i.e. is highly soluble and permeable) and has a short halflife $(2.4 \mathrm{~h})$, the decrease in $C_{\max }$ when given with food is unlikely to result from a change in solubility or permeability. One possibility is that it results from slower gastric emptying rate in the fed state. The high coefficient of variation for the PK parameters observed in both the fasted and fed arms of the study (Table 5) is consistent with the wide interindividual variation in gastric emptying. ${ }^{[1,16,30-32]}$

The clinical study was conducted exclusively in male patients, which is worth noting because women tend to exhibit higher zolpidem exposure than men. Interestingly, a gender effect on the pharmacokinetics of zolpidem has been reported not only for immediate-release tablets but also for other types of zolpidem formulation, such as sublingual and modified-release tablets $\left(\right.$ Ambien $\left.\mathrm{CR}^{\circledR}\right) \cdot[15,16,33,34]$

\section{Dissolution experiments used to build the PBPK model for zolpidem in the fasted state}

\section{Fasted state dissolution}

Figure 2 shows the dissolution profile of Stilnox ${ }^{\circledR} 10 \mathrm{mg}$ tablets in biorelevant media simulating the gastric 


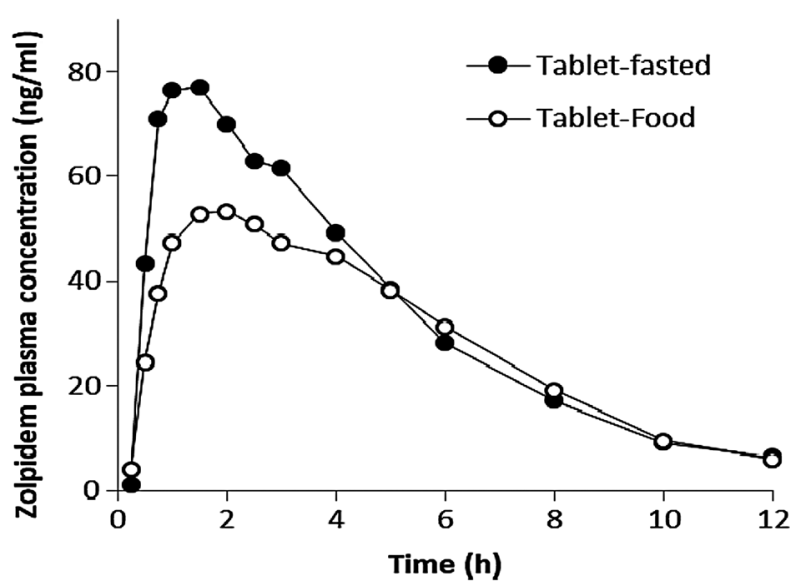

Figure 1 Mean plasma zolpidem concentration after oral administration of $10 \mathrm{mg}$ immediate-release Stilnox ${ }^{\circledR}$ under fasting and fed conditions.

Table 5 Summary of descriptive statistics of zolpidem PK parameters after a single oral administration of zolpidem $10 \mathrm{mg}$ immediate release $\left(\right.$ Stilnox ${ }^{\circledR}$ ) under fasted and fed conditions

\begin{tabular}{|c|c|c|c|c|c|c|}
\hline & \multirow{2}{*}{$\begin{array}{l}T_{\max } \\
\text { (h) }\end{array}$} & \multirow{2}{*}{$\begin{array}{l}C_{\max } \\
(\mathrm{ng} / \mathrm{ml})\end{array}$} & \multirow{2}{*}{$\begin{array}{l}\mathrm{AUC}_{0-12 \mathrm{~h}} \\
(\mathrm{ng} / \mathrm{ml} . \mathrm{h})\end{array}$} & \multicolumn{3}{|c|}{ Food effect (fed/fasted) } \\
\hline & & & & $T_{\max }$ & $C_{\max }$ & $\mathrm{AUC}_{0-12 \mathrm{~h}}$ \\
\hline $\begin{array}{l}\text { Fasted } \\
\text { mean } \\
\text { (CV\%) }\end{array}$ & $\begin{array}{l}1.36 \\
(66)\end{array}$ & $\begin{array}{l}100.1 \\
(42)\end{array}$ & $\begin{array}{l}398.9 \\
(56)\end{array}$ & - & - & - \\
\hline $\begin{array}{l}\text { Fed } \\
\text { mean } \\
\text { (CV\%) }\end{array}$ & $\begin{array}{l}2.16 \\
(72)\end{array}$ & $\begin{array}{l}75.5 \\
(43)\end{array}$ & $\begin{array}{l}344.0 \\
(52)\end{array}$ & 1.59 & 0.76 & 0.86 \\
\hline
\end{tabular}

(FaSSGF) and upper intestinal (FaSSIF-V2) environment in the fasted state. The rate and extent of dissolution was almost superimposable in the two media, indicating that the dissolution of zolpidem tablets is expected to be similar in these two regions of the gastrointestinal tract.

Simulation of the observed PK data using the fasted state PBPK model. To simulate the fasted state plasma profile of zolpidem, the PBPK model in Simcyp ${ }^{\circledR}$ was built using the biopharmaceutical, physicochemical and pharmacokinetic drug properties listed in Table 4 and the data obtained from the biorelevant dissolution tests. The default values for a healthy, male volunteer population in the fasted state (along with known variability in parameters) were chosen, and the simulation was run ten times so that the 5th and 95th percentiles for the population could be estimated. Figure 3 depicts the simulated and observed mean plasma concentration profiles of zolpidem in the fasted state.

Table 6 summarizes the calculated PK parameters $\left(T_{\max }\right.$, $C_{\max }$ and AUC), along with AFE and AAFE values. The results indicate that dissolution in FaSSGF and FaSSIF-V2

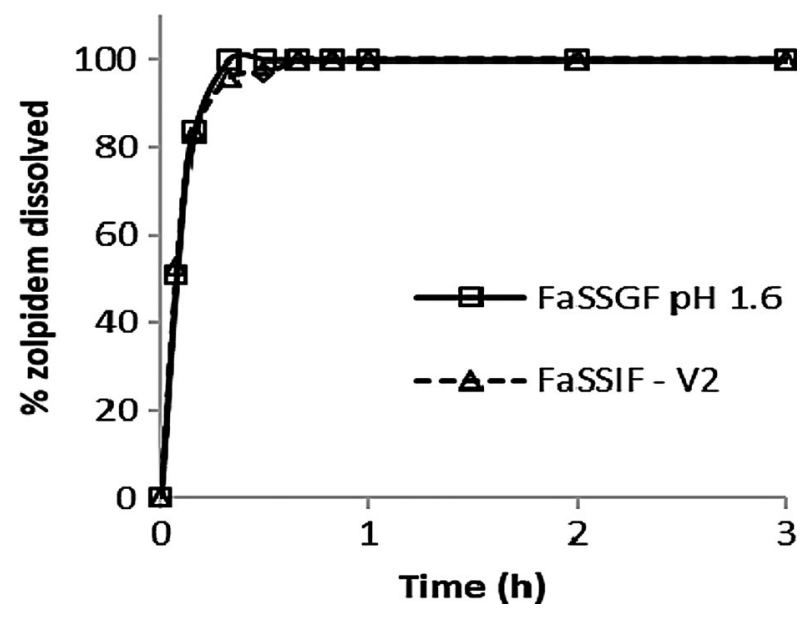

Figure 2 Mean dissolution profiles of $10 \mathrm{mg}$ immediate-release Stilnox ${ }^{\circledR}$ tablets in biorelevant Level II dissolution media simulating the fasted state using USP apparatus II. Error bars lie within the symbols in all cases.

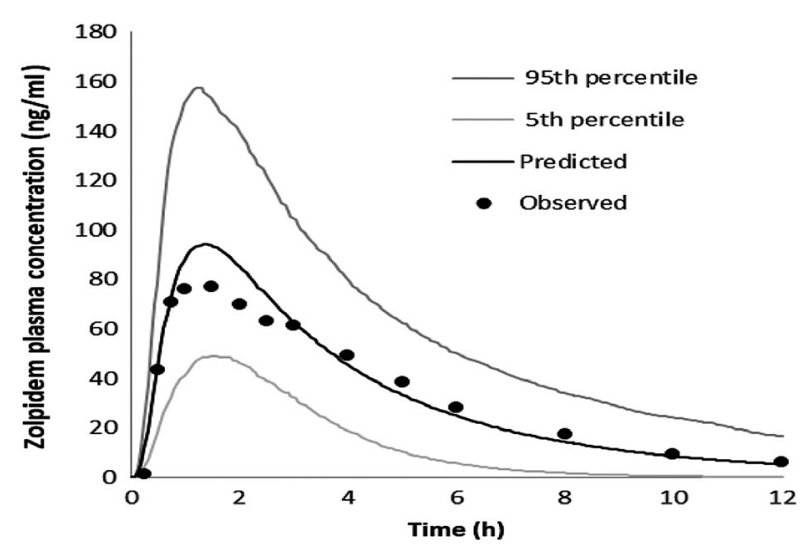

Figure 3 Simulated (mean, 5th percentile and 95th percentile) and observed mean plasma zolpidem concentrations after zolpidem administration in the fasted state.

provided an appropriate simulation of the in-vivo behaviour of zolpidem formulation in the fasted state: the observed mean plasma profile and the PK parameters ( $T_{\max }, C_{\max }$ and AUC) lie well within the profiles simulated on the basis of the biorelevant dissolution experiments, taking into account the variability in physiology in this population. Furthermore, the AFE and AAFE values lie well under 2.

Parameter sensitivity analysis to determine the effect of gastric emptying time in the zolpidem $P K$ profile. To investigate the influence of gastric emptying time (GET) on the PK profile of zolpidem in the fasted state, a parameter sensitivity analysis (PSA) was conducted. The GET values were allowed to float over the range of $0.1-2 \mathrm{~h}$, with the latter corresponding approximately to the duration of the 
motility cycle in the fasted state. The results are shown in Figure 4 .

The results are generally consistent with the expected behaviour of BCS class I drugs with short half-lives dosed in fast-releasing dosage forms. At longer gastric emptying times, the in-vivo $C_{\max }$ and AUC are underpredicted and the $T_{\max }$ is overpredicted. The simulations came closest to the observed mean $C_{\max }$ when a GET of 0.6 or $0.9 \mathrm{~h}$ was used for the simulation; however, the $T_{\max }$ was best simulated by a GET of $0.1 \mathrm{~h}$. These simulations suggest that, although GET has a large influence on the plasma profile, factors other than GET may also play a role in zolpidem absorption. Comparison of the range of concentrations reached over this large variation in gastric emptying with the $5^{\text {th }}$ and $95^{\text {th }}$ percentile curves shown in Figure 3 , which reflect overall variability in the physiological parameters of the patient population, support this hypothesis.

\section{Biorelevant dissolution to build the PBPK model for zolpidem in the fed state}

In order to simulate dissolution conditions in the postprandial stomach, Lipofundin MCT 20, an emulsion often utilized for parenteral nutrition, was added to the media in various concentrations and the $\mathrm{pH}$ was also adjusted to reflect the gradual return to baseline $\mathrm{pH}$ after meal ingestion.

Additional tests were run for all three FeSSGF versions at a higher $(7.5 \%)$ fat content to investigate the influence of high-fat content on zolpidem release. Figure $5 \mathrm{a}$ shows the dissolution profiles of Stilnox ${ }^{\circledR}$ tablets in the media simulating the gastric environment during different periods after food ingestion, with and without increasing the fat concentration to $7.5 \%$.

Of the media representing the stomach during different periods after meal ingestion, the dissolution of zolpidem

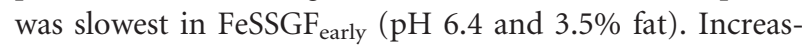
ing the fat content of FeSSGF early $_{\text {to }} 7.5 \%$ slowed the dissolution rate even further. The dissolution rate of zolpidem from the Stilnox ${ }^{\circledR}$ tablets was highest in FeSSGF ${ }_{\text {late }}(\mathrm{pH} 3.0$ and $0.88 \%$ fat) and increasing the fat content from 0.88 to $7.5 \%$ in this medium made little or no difference to the rate of dissolution in this case. The results for FeSSGF middle $_{\text {fell }}$ between those in the early and late media.

\section{Simulation of the observed data using the fed state PBPK model}

Simulation using variations in the level of $\mathrm{pH}$ and fat content. To simulate the plasma profile in the fed state, the same structural model as used for predicting the fasted state was applied. All parameters (Table 4) were kept constant to simulate the plasma profiles observed in the fed state, except that (1) the dissolution data obtained under conditions representing the fed state were applied, and (2) the default values for the Stilnox ${ }^{\circledR}$ healthy male population in the fed state were implemented.

Insertion of the data obtained from testing of dissolution in the early and late version of FeSSGF into the PBPK model (Figure 5b) generally resulted in an excellent fit of the observed mean fed state plasma profile. The only exception was the results from the early FeSSGF medium at the higher fat content of $7.5 \%$, which was lower than the other simulated profiles. The pharmacokinetic parameters $\left(C_{\max }\right.$, AUC and $T_{\max }$ ) from the simulations were used to calculate the goodness of fit (AFE and AAFE). The values are presented in Table 7.

The AAFE values for all media were lower than 2, indicating acceptable simulation of the in-vivo results. However, the best simulations in terms of AFE and AAFE were

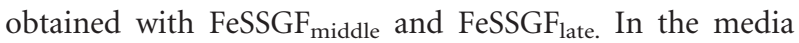
simulating a high fat $(7.5 \%)$ in the stomach, the AFE values were slightly to moderately below 1.0 , indicating that the observed profile was underpredicted. The effect was most

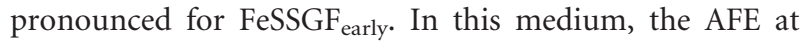
$3.5 \%$ fat (standard value) was 0.85 and at $7.5 \%$ fat it was 0.71 , and thus further from the ideal value of 1.0.

The early FeSSGF medium, which reflects an initial elevation in the gastric $\mathrm{pH}$ induced by food intake, may have prevented the dosage form from completely disintegrating. Another ramification of a high $\mathrm{pH}$ early after meal ingestion for weak bases like zolpidem (pKa 6.06) would be a reduction in the solubility and therefore dissolution rate, although this effect is expected to be less important for

Table 6 Pharmacokinetic parameters of zolpidem for the food effect study with the corresponding simulation results using in-vitro data input from biorelevant dissolution tests simulating the fasted state

\begin{tabular}{lclll}
\hline $\begin{array}{l}\text { Pharmacokinetic } \\
\text { parameters }\end{array}$ & $\begin{array}{l}\text { Simulated - FaSSGF } \\
\text { and FaSSIF-V2 media }\end{array}$ & Observed - fasted & $\begin{array}{l}\text { \% difference } \\
\text { (simulated - observed) }\end{array}$ & AFE/AAFE \\
\hline $\mathrm{C}_{\max }(\mathrm{ng} / \mathrm{mL})$ & 94.2 & $100.1(42)$ & -5.88 \\
AUC $_{0-12}(\mathrm{ng} \cdot \mathrm{h} / \mathrm{mL})$ & 404.7 & $398.9(56)$ & 1.45 & 0.73 \\
$\mathrm{~T}_{\max }(\mathrm{h})$ & 1.35 & 1.36 & & 1.01 \\
AFE & - & & & 1.64 \\
\hline AAFE & - & & \\
\hline
\end{tabular}




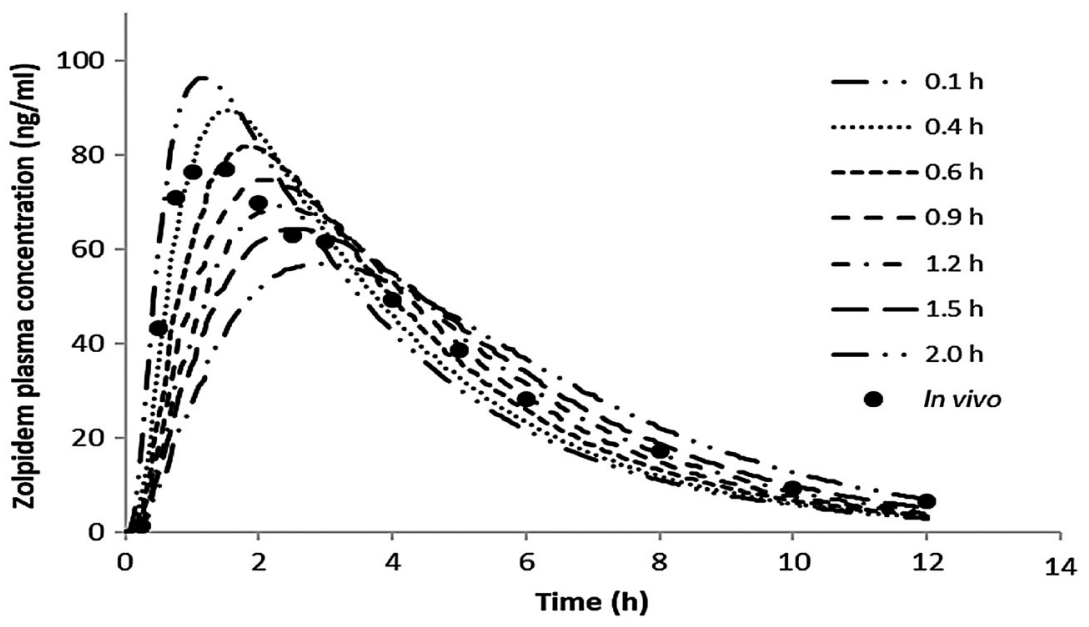

Figure 4 Zolpidem pharmacokinetic profile, applying parameter sensitivity analysis on gastric emptying time in the fasted state.
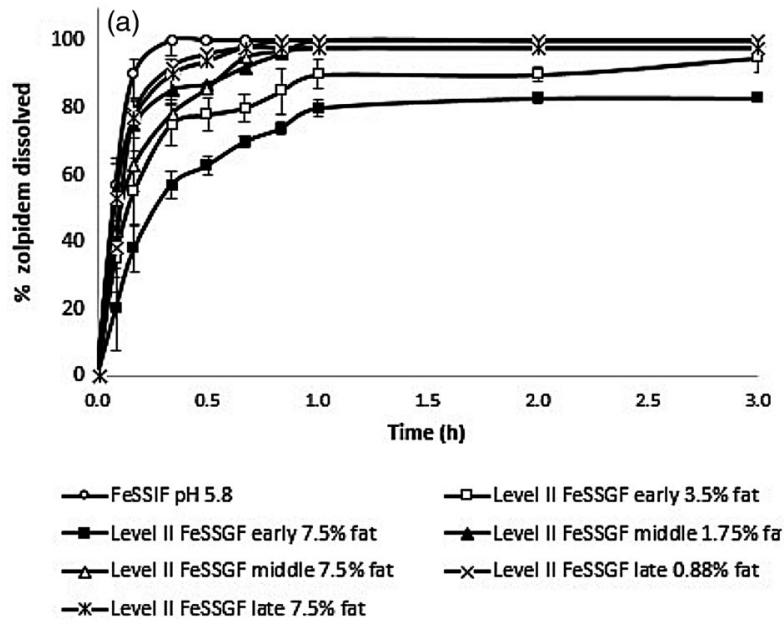

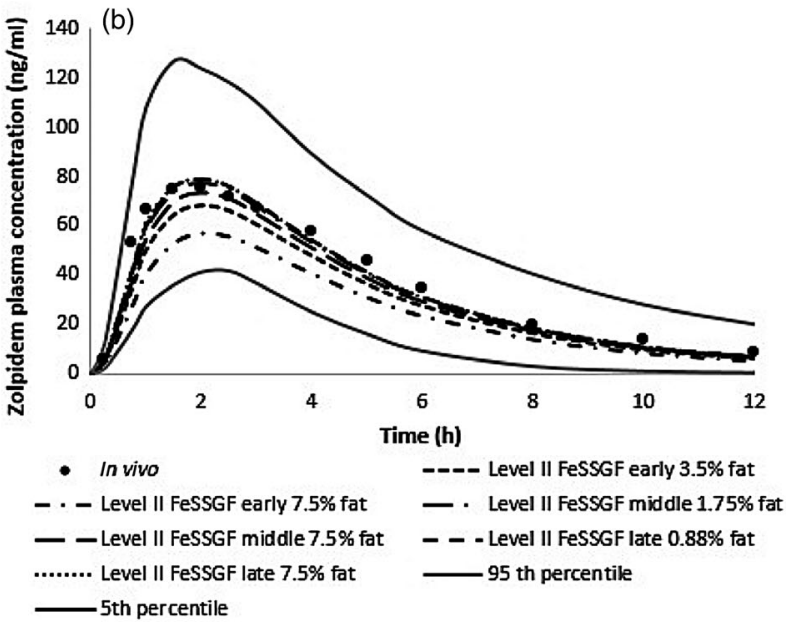

Figure 5 (a) Mean ( \pm standard deviation) dissolution profiles of $10 \mathrm{mg}$ immediate-release Stilnox ${ }^{\circledR}$ tablets in biorelevant Level II dissolution media representing the fed state to explore the effect of fat and $\mathrm{pH}$ on drug release, using USP apparatus II. (b) Simulated and observed plasma concentration profile of zolpidem using different biorelevant dissolution profiles. The 5th and 95th percentiles are for the simulations with FeSSGF ${ }_{\text {middle. }}$

highly soluble weak bases like zolpidem. Either or both of these factors could have contributed to prediction of slower absorption and hence a reduction in $C_{\max }$ in the fed state simulations.

Parameter sensitivity analysis to investigate the effect of gastric emptying time in the fed state zolpidem $P K$ profile. To investigate the influence of the GET on the PK profile of zolpidem in the fed state, a PSA analogous to the one for the fasted state was conducted. For the fed state, the GET values were floated over the range $0.1-4 \mathrm{~h}$. The longer GET in the fed compared with the fasted state was based on literature data. ${ }^{[31,32]}$ The PSA of GET for the fed state simulation is shown in Figure 6.

As for the fasted state, the longer gastric emptying time, the lower the calculated $C_{\max }$ and AUC and the longer the $T_{\max }$. Due to the larger range of GET values applied, the changes in the pharmacokinetic parameters appear more pronounced than for the fasted state. The best fit for $T_{\max }$ was found at $0.7 \mathrm{~h}$ while the best fit for $C_{\max }$ was at $1.8 \mathrm{~h}$. As for the fasted state, it appears that other mechanisms are also involved to some extent in determining the variation in plasma profiles.

\section{Biorelevant dissolution to investigate effect of hydroxypropylmethylcellulose and $\mathrm{pH}$ on the release of the drug}

The results of the dissolution tests simulating an increase in gastric fluid viscosity with 0.5 or $1.4 \%$ HPMC are presented in Figure 7a. Due to the high viscosity of the medium with $1.4 \% \mathrm{HPMC}$, it was necessary to increase the duration of sampling from 3 to $6 \mathrm{~h}$ and even then it was not possible to reach a drug release of $100 \%$. It may be assumed that poor 
Table 7 Pharmacokinetic parameters of zolpidem from the bioavailability and food effect studies with the corresponding simulation results using in-vitro data input from experimental conditions to simulate the effect of $\mathrm{pH}$ and high-fat dissolution experiments

\begin{tabular}{|c|c|c|c|c|c|c|c|}
\hline \multirow[b]{2}{*}{ Media } & \multirow[b]{2}{*}{$\begin{array}{l}\text { Pharmacokinetic } \\
\text { parameters }\end{array}$} & \multirow[b]{2}{*}{$\begin{array}{l}\text { Parameter value } \\
\text { predicted from } \\
\text { fed state media }\end{array}$} & \multicolumn{2}{|l|}{ Observed } & \multirow{2}{*}{$\begin{array}{l}\text { Food effect } \\
\text { (Simulated fed vs. } \\
\text { observed } \\
\text { fasted data) }\end{array}$} & \multirow{2}{*}{$\begin{array}{l}\% \text { difference } \\
\text { observed - } \\
\text { predicted } \\
\text { (fed state) }\end{array}$} & \multirow{2}{*}{$\begin{array}{l}\text { AFE/AAFE } \\
\text { observed } \\
\text { predicted } \\
\text { (fed state) }\end{array}$} \\
\hline & & & Fed & Fasted & & & \\
\hline FeSSGF & $C_{\max }(n g / m L)$ & 68.1 & $75.5(43)$ & $100.1(42)$ & 0.68 & -10.04 & - \\
\hline $\mathrm{pH} 6.4$ & $\mathrm{AUC}_{0-12}(\mathrm{ng} \cdot \mathrm{h} / \mathrm{mL})$ & 361.0 & $344.0(52)$ & $398.9(56)$ & 0.90 & 4.94 & - \\
\hline \multirow[t]{3}{*}{$3.5 \%$ fat } & $\mathrm{T}_{\max }(\mathrm{h})$ & 2.0 & $2.16(72)$ & $1.36(66)$ & 1.47 & -7.40 & - \\
\hline & AFE & - & - & - & - & - & 0.85 \\
\hline & AAFE & - & - & - & - & - & 1.45 \\
\hline FeSSGF middle & $C_{\max }(n g / m L)$ & 77.7 & $75.5(43)$ & $100.1(42)$ & 0.78 & 2.64 & - \\
\hline pH 5.0 & $\mathrm{AUC}_{0-12}(\mathrm{ng} \cdot \mathrm{h} / \mathrm{mL})$ & 408.8 & $344.0(52)$ & $398.9(56)$ & 1.02 & 18.84 & - \\
\hline \multirow[t]{3}{*}{$1.75 \%$ fat } & $\mathrm{T}_{\max }(\mathrm{h})$ & 1.99 & $2.16(72)$ & $1.36(66)$ & 1.46 & -7.87 & - \\
\hline & AFE & - & - & - & - & - & 0.98 \\
\hline & AAFE & - & - & - & - & - & 1.34 \\
\hline FeSSGF late & $\mathrm{C}_{\max }(\mathrm{ng} / \mathrm{mL})$ & 78.7 & $75.5(43)$ & $100.1(42)$ & 0.79 & 3.96 & - \\
\hline $\mathrm{pH} 3.0$ & $\mathrm{AUC}_{0-12}(\mathrm{ng} \cdot \mathrm{h} / \mathrm{mL})$ & 413.0 & $344.0(52)$ & $398.9(56)$ & 1.03 & 20.05 & - \\
\hline \multirow[t]{3}{*}{$0.88 \%$ fat } & $\mathrm{T}_{\max }(\mathrm{h})$ & 1.95 & $2.16(72)$ & $1.36(66)$ & 1.43 & -9.72 & - \\
\hline & AFE & - & - & - & - & & 0.98 \\
\hline & AAFE & - & - & - & - & & 1.33 \\
\hline \multirow{5}{*}{$\begin{array}{l}\text { FeSSGF } \text { early } \\
\mathrm{pH} 6.4 \\
7.5 \% \text { fat }\end{array}$} & $C_{\max }(n g / m L)$ & 57.1 & $75.5(43)$ & $100.1(42)$ & 0.57 & -24.57 & - \\
\hline & $A \cup C_{0-12}(\mathrm{ng} \cdot \mathrm{h} / \mathrm{mL})$ & 304.7 & $344.0(52)$ & $398.9(56)$ & 0.76 & -11.42 & - \\
\hline & $\mathrm{T}_{\max }(\mathrm{h})$ & 2.05 & $2.16(72)$ & $1.36(66)$ & 1.51 & -5.09 & - \\
\hline & AFE & - & - & - & - & & 0.71 \\
\hline & AAFE & - & - & - & - & & 1.67 \\
\hline \multirow{5}{*}{$\begin{array}{l}\text { FeSSGF middle } \\
\text { pH } 5.0 \\
7.5 \% \text { fat }\end{array}$} & $C_{\max }(\mathrm{ng} / \mathrm{mL})$ & 73.5 & $75.5(43)$ & $100.1(42)$ & 0.73 & -2.9 & - \\
\hline & $A_{U} C_{0-12}(\mathrm{ng} \cdot \mathrm{h} / \mathrm{mL})$ & 387.7 & $344.0(52)$ & $398.9(56)$ & 0.97 & 12.7 & - \\
\hline & $\mathrm{T}_{\max }(\mathrm{h})$ & 2.00 & $2.16(72)$ & $1.36(66)$ & 1.47 & -7.4 & - \\
\hline & AFE & - & - & - & - & - & 0.92 \\
\hline & AAFE & - & - & - & - & - & 1.38 \\
\hline \multirow{5}{*}{$\begin{array}{l}\text { FeSSGF } \\
\mathrm{pH} 3.0 \\
7.5 \% \text { fat }\end{array}$} & $C_{\max }(n g / m L)$ & 79.4 & $75.5(43)$ & $100.1(42)$ & 0.79 & 4.89 & - \\
\hline & $\mathrm{AUC}_{0-12}(\mathrm{ng} \cdot \mathrm{h} / \mathrm{mL})$ & 416.6 & $344.0(52)$ & $398.9(56)$ & 1.04 & 21.10 & - \\
\hline & $\mathrm{T}_{\max }(\mathrm{h})$ & 1.93 & $2.16(72)$ & $1.36(66)$ & 1.42 & -10.64 & - \\
\hline & AFE & - & - & - & - & - & 0.99 \\
\hline & AAFE & - & - & - & - & - & 1.33 \\
\hline
\end{tabular}

wetting and reduced hydrodynamic shear rate in viscous media contributed to the slow and incomplete dissolution of the drug.

Simulations using variations in viscosity. The results from the dissolution studies simulating the increase in viscosity of the stomach contents were integrated in the PBPK model to obtain the simulated mean plasma concentration profile of zolpidem, as shown in Figure $7 \mathrm{~b}$. From the simulations, the pharmacokinetic parameters $C_{\max }, T_{\max }$ and AUC were calculated and these are presented together with the AFE and AAFE values in Table 8.

In all media simulating the increase of viscosity with 0.5 and $1.4 \%$ of HPMC, the AFE values were $<1.0$, indicating that these media underpredict the observed mean plasma profile (Figure $7 \mathrm{~b}$ ). Further, the underprediction of the pharmacokinetic parameters was more pronounced for the media containing 1.4\% HPMC.
In the media with highest viscosity (1.4\% HPMC), the values obtained from AFE for FeSSGF middle and FeS$\mathrm{SGF}_{\text {late }}$ were, respectively, 0.31 and 0.21 , very far from the ideal value of 1.0, and values of AAFE were higher than 2 and therefore not considered acceptable. The AAFE values for 0.5\% HMPC media were below 2 and thus would be considered acceptable, but with AFE values of 0.66 for FeSSGF middle and 0.75 for FeSSGF late, media with $0.5 \%$ HPMC appear to be less suitable for simulating the in-vivo behaviour than the standard biorelevant media. Further, the FeSSGF late dissolution results predicted a mean maximum concentration plasma below the $5^{\text {th }}$ percentile value obtained in the FeSSGF middle simulations and far lower than the observed mean $C_{\max }$ of just over $75 \mathrm{ng} / \mathrm{ml}$. Taken together, these values indicate that, for zolpidem immediate-release tablets, the high-viscosity media do not reflect the dissolution process in-vivo adequately. 




Figure 6 Parameter sensitivity analysis of the zolpidem pharmacokinetic profile for gastric emptying time in the fed state.

In addition to the reduction of the hydrodynamic shear stress in the stomach, poor disintegration, potential complexation or a decrease in drug diffusivity are some further theories that have been put forward to explain the alteration of absorption of drugs in the fed state. Studies have demonstrated that viscosity is inversely proportional to the diffusivity of particles in the gastric content, which in turn could influence the disintegration of tablet and dissolution of drugs ${ }^{[32]}$. But it seems that these factors are not of primary importance in the case of zolpidem immediate-release tablets.

\section{Influence of meal intake on gastric physiology}

Food intake is known to influence gastric emptying time due to the increase in caloric content, increase in stomach $\mathrm{pH}$, viscosity and fat content, and by initiating lipid digestion. ${ }^{[1,30-32,35]}$ Thus, when a solid oral drug formulation is administered postprandially, the absorption profile of the drug is often altered. ${ }^{[36-38]}$

For drugs with low solubility, such as those assigned to BCS class II, the presence of fat and its digestion products in the stomach can improve the solubility and dissolution of the compound, resulting in an increase in the absorbed fraction of the drug. ${ }^{[1]}$

Drugs that belong to BCS class III can show a negative food effect. Some drugs in this class exhibit regionally dependent absorption, with best permeability in the upper small intestine (due to e.g. active or paracellular transport mechanisms). Therefore, any interaction with food that compromises the availability of the drug for absorption in this region could result in a significant decrease in the bioavailability of the drug. ${ }^{[1]}$ This mechanism has been proposed for bidisomide. ${ }^{[37]}$ Another example of a negative food effect for a BCS class III drug is avitriptan. Food effect studies with this drug suggested that the negative food effect for avitriptan is associated with a greater first-pass effect when it is ingested with a meal, whereby the slower delivery of drug to the metabolizing enzymes involved in first-pass results in an increase in the efficiency of metabolism of avitriptan. ${ }^{[36]}$

On the other hand, for drugs that belong to BCS class I and which are rapidly released in the stomach and absorbed from the proximal small intestine, the gastric emptying time (GET) can be critical to the absorption rate. ${ }^{[1,37]}$ Therefore, factors that delay the gastric emptying may delay absorption of such drugs. For example, a high-fat content in the meal is known to decrease the gastric emptying rate due to the high-calorie content ( $9 \mathrm{kcal} / \mathrm{g}$ ) of fats. While the results obtained in this study showed that an increase in the fat content of the media also tends to slow the dissolution of zolpidem in some cases, the effect is not large enough to fully explain the difference in the mean plasma profiles between the fasted and fed states.

A further effect of meal intake is to increase the viscosity of the gastric contents. This can lead to formation of a 'film layer' on the surface of the tablet resulting in a decrease in the rate of penetration of the medium into the tablet and impeding the wetting and disintegration of the tablet invivo, ${ }^{[11,31,39-41]}$ likely due to the presence of proteins and carbohydrates. Developing a dissolution medium which is capable of mimicking the increase in the viscosity of the gastrointestinal contents and its effects on dosage form disintegration is therefore of great importance. Due to factors such as the amount of food ingested, fluids ingested with the meal as well as the rate of saliva and gastric juice secretion, the composition and viscosity of chyme are highly variable. ${ }^{[31,42-45]}$ Various authors have proposed dissolution media to simulate the increase in the viscosity of gastric content using soup or various gelling agents such as guar gum, potato granules, HPMC and hydroxyethylcellulose to adjust the meal viscosity. ${ }^{[8,11,39,40]}$ The large range of viscosities implemented in these studies demonstrate that it is difficult to identify a specific viscosity value that can be recommended for biorelevant media. Although the HPMC media applied in the zolpidem studies certainly provide a good qualitative description of the food effect, further work needs to be done in this area to arrive at a more quantitatively predictive dissolution method.

Since the immediate-release dosage form of zolpidem is used for sleep induction, the food effect study was conducted overnight and in the supine position. It is known that there is a profound inhibitory effect on gastrointestinal (GI) motility pattern during sleep. Several studies have demonstrated the suppression of both gastric and colonic motilities. ${ }^{[46-49]}$ On the other hand, the delay in gastric emptying due to the supine position is controversial. Some studies have shown no significant effect of body position in the gastric emptying time, ${ }^{[50-52]}$ whereas 


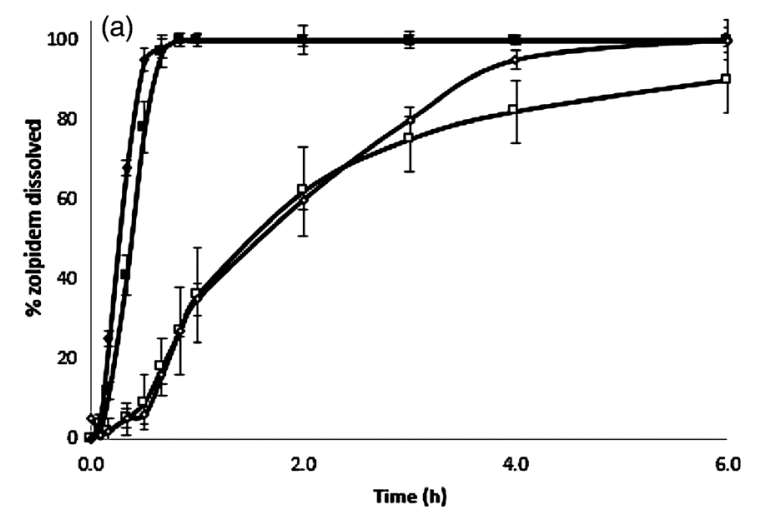

LLevel II FeSSGF middle with 0.5\% HPMC $[$ Level II FeSSGF middle with 1.4\% HPMC

$\rightarrow$ Level II FeSSGF late with $0.5 \%$ HPMC

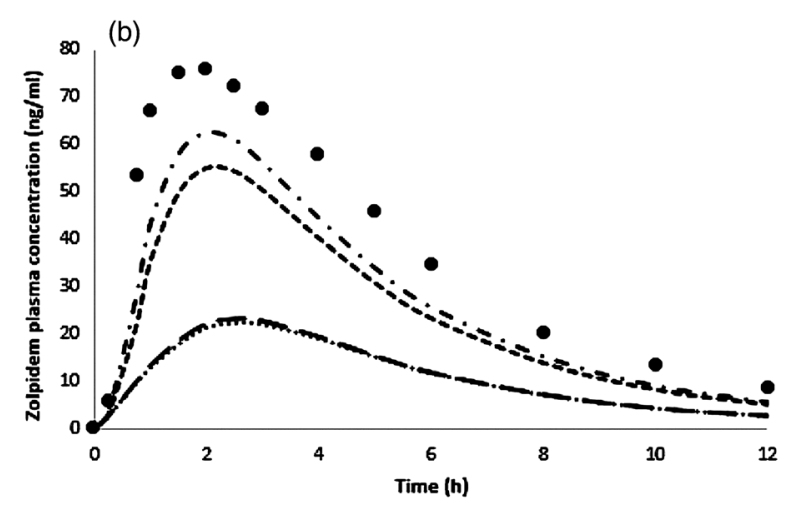

- In vivo ---Level II FeSSGF middle with 0.5\% HPMC

Figure 7 (a) Mean ( \pm standard deviation) dissolution profiles of $10 \mathrm{mg}$ immediate-release Stilnox ${ }^{\circledR}$ tablets in biorelevant Level $I I$ dissolution media in the fed state to explore the effect of $\mathrm{pH}$ and viscosity on drug release, using USP apparatus II. (b) Simulated and observed plasma concentration profile of zolpidem using various dissolution profiles.

Table 8 Pharmacokinetic parameters of zolpidem for the food effect studies with the corresponding simulation results using in-vitro data input from experimental conditions simulating the effect of $\mathrm{pH}$ and high viscosity (hydroxypropylmethylcellulose (HPMC)) on release from Stilnox ${ }^{\circledR}$ $10 \mathrm{mg}$ immediate-release tablets

\begin{tabular}{|c|c|c|c|c|c|c|c|}
\hline \multirow[b]{2}{*}{ Media } & \multirow[b]{2}{*}{$\begin{array}{l}\text { Pharmacokinetic } \\
\text { parameters }\end{array}$} & \multirow[b]{2}{*}{$\begin{array}{l}\text { Parameter value } \\
\text { predicted from } \\
\text { fed state media }\end{array}$} & \multicolumn{2}{|l|}{ Observed } & \multirow{2}{*}{$\begin{array}{l}\text { Food effect } \\
\text { (Simulated fed vs. } \\
\text { observed } \\
\text { fasted data) }\end{array}$} & \multirow{2}{*}{$\begin{array}{l}\% \text { difference } \\
\text { observed - } \\
\text { predicted } \\
\text { (fed state) }\end{array}$} & \multirow{2}{*}{$\begin{array}{l}\text { AFE/AAFE } \\
\text { observed } \\
\text { predicted } \\
\text { (fed state) }\end{array}$} \\
\hline & & & Fed & Fasted & & & \\
\hline \multirow{5}{*}{$\begin{array}{l}\text { FeSSGF middle } \\
\text { pH } 5.0 \\
0.5 \% \text { HPMC }\end{array}$} & $\mathrm{Cmax}(\mathrm{ng} / \mathrm{mL})$ & 23.0 & $75.5(43)$ & $100.1(42)$ & 0.23 & -69.62 & - \\
\hline & $\mathrm{AUC}_{0-12}(\mathrm{ng} \cdot \mathrm{h} / \mathrm{mL})$ & 135.0 & $344.0(52)$ & $398.9(56)$ & 0.33 & -60.75 & - \\
\hline & $\mathrm{T}_{\max }(\mathrm{h})$ & 2.6 & $2.16(72)$ & $1.36(66)$ & 1.91 & 20.37 & - \\
\hline & AFE & - & - & - & - & - & 0.66 \\
\hline & AAFE & - & - & - & - & - & 1.47 \\
\hline \multirow{5}{*}{$\begin{array}{l}\text { FeSSGF late } \\
\text { pH } 3.0 \\
0.5 \% \text { HPMC }\end{array}$} & $C_{\max }(n g / m L)$ & 62.6 & $75.5(43)$ & $100.1(42)$ & 0.62 & -17.30 & - \\
\hline & $\mathrm{AUC}_{0-12}(\mathrm{ng} \cdot \mathrm{h} / \mathrm{mL})$ & 331.6 & $344.0(52)$ & $398.9(56)$ & 0.83 & -3.60 & - \\
\hline & $T_{\max }(h)$ & 2.12 & $2.16(72)$ & $1.36(66)$ & 1.56 & -1.85 & - \\
\hline & AFE & - & - & - & - & - & 0.75 \\
\hline & AAFE & - & - & - & - & - & 1.35 \\
\hline \multirow{5}{*}{$\begin{array}{l}\text { FeSSGF middle } \\
\text { pH } 5.0 \\
1.4 \% \text { HPMC }\end{array}$} & $\mathrm{C}_{\max }(\mathrm{ng} / \mathrm{mL})$ & 54.9 & $75.5(43)$ & $100.1(42)$ & 0.55 & -27.48 & - \\
\hline & $\mathrm{AUC}_{0-12}(\mathrm{ng} \cdot \mathrm{h} / \mathrm{mL})$ & 293.0 & $344.0(52)$ & $398.9(56)$ & 0.73 & -14.82 & - \\
\hline & $T_{\max }(h)$ & 2.18 & $2.16(72)$ & $1.36(66)$ & 1.60 & 0.92 & - \\
\hline & AFE & - & - & - & - & - & 0.31 \\
\hline & AAFE & - & - & - & - & - & 2.26 \\
\hline \multirow{5}{*}{$\begin{array}{l}\text { FeSSGF late } \\
\text { pH } 3.0 \\
1.4 \% \text { HPMC }\end{array}$} & $C_{\max }(\mathrm{ng} / \mathrm{mL})$ & 22.2 & $75.5(43)$ & $100.1(42)$ & 0.22 & -70.67 & - \\
\hline & $\mathrm{AUC}_{0-12}(\mathrm{ng} \cdot \mathrm{h} / \mathrm{mL})$ & 132.4 & $344.0(52)$ & $398.9(56)$ & 0.33 & -61.51 & - \\
\hline & $\mathrm{T}_{\max }(\mathrm{h})$ & 2.65 & $2.16(72)$ & $1.36(66)$ & 1.94 & 22.68 & - \\
\hline & AFE & - & - & - & - & - & 0.21 \\
\hline & AAFE & - & - & - & - & - & 2.49 \\
\hline
\end{tabular}

others have shown differences in GET due to changes in body position. ${ }^{[53-55]}$

The delay in GET provoked by the circadian cycle, together with the ingestion of food with high caloric content, may be responsible at least partially for the decrease in the rate $\left(C_{\max }\right)$ and extent (AUC) of absorption of zolpidem. Although the administration of zolpidem tablets in the fasted state would be preferable, both for optimization of efficacy and assurance of safety, most people do not like to go to bed on an empty stomach. 


\section{Conclusions}

This work demonstrated that the combination of two widely used biopharmaceutics tools, biorelevant dissolution testing and PBPK modelling, is a useful way forward to characterize the in-vivo behaviour of zolpidem after administering $10 \mathrm{mg}$ immediate-release tablets as well as to attain a more mechanistic understanding of the influence of food in the process of zolpidem absorption. The PBPK model predicted the clinical data of zolpidem from the food effect study well by combining data from in-vitro biorelevant dissolution experiments simulating the fasted and fed states together with PBPK modelling using parameters from the literature.

Additional experiments to evaluate the influence of increasing the viscosity of the media to simulate fed state conditions failed to provide a quantitative description of the in-vivo behaviour of zolpidem. Results of experiments that evaluated the effect of high amounts of fat on dissolution in the fed stomach suggested that there is no direct relationship between the increasing the amount of fat in the stomach and the release of zolpidem over most of the postprandial period. However, this higher fat content may lead to a lower $C_{\max }$ by reducing the gastric emptying rate.
The gastric emptying time appears to be the most important factor determining the onset action and peak exposure of zolpidem, although other factors may also play a role.

In summary, biorelevant dissolution methodology coupled with PBPK modelling provides an appropriate means for predicting how drugs are absorbed in the human fasted and fed states and for investigating the mechanisms behind food effects. The approach can contribute significantly to the drug development process, saving time and costs associated with bringing new drug products to the market.

\section{Declarations}

\section{Conflict of interest}

The Author(s) declare(s) that they have no conflicts of interest to disclose.

\section{Acknowledgements}

This work was supported by the European Union's Horizon 2020 Research and Innovation Programme under grant agreement No 674909 (PEARRL).

\section{References}

1. Fleisher D et al. Drug, meal and formulation interactions influencing drug absorption after oral administration clinical implications. Clin Pharmacokinet 1999; 36: 233-254.

2. Greenblatt DJ et al. Drug interactions with grapefruit juice: an update. J Clin Psychopharmacol 2001; 21: 357-359.

3. Hanley MJ et al. The effect of grapefruit juice on drug disposition. Expert Opin Drug Metab Toxicol 2011; 7: 267-286.

4. Schmidt LE, Dalhoff K. Food-drug interactions. Drugs 2002; 62: 14811502.

5. Singh BN. Effects of food on clinical pharmacokinetics. Clin Pharmacokinet 1999; 37: 213-255.

6. Burggraaf $\mathrm{J}$ et al. Assessment of changes in liver blood flow after food intake-comparison of ICG clearance and echo-Doppler. $\mathrm{Br} J$ Clin Pharmacol 1996; 42: 499-502.

7. Charman WN et al. Physiochemical and physiological mechanisms for the effects of food on drug absorption: the role of lipids and pH. J Pharm Sci 1997; 86: 269-282.

8. Radwan A et al. Mechanistic investigation of food effect on disintegration and dissolution of BCS class III compound solid formulations: the importance of viscosity. Biopharm Drug Dispos 2012; 33: 403-416.

9. Abuhelwa AY et al. A quantitative review and meta-models of the variability and factors affecting oral drug absorption-Part I: gastrointestinal $\mathrm{pH}$. AAPS J 2016; 18: 1309-1321.

10. Abuhelwa AY et al. Food, gastrointestinal $\mathrm{pH}$, and models of oral drug absorption. Eur J Pharm Biopharm 2017; 112: 234-248.

11. Radwan A et al. Food effect: the combined effect of media $\mathrm{pH}$ and viscosity on the gastrointestinal absorption of ciprofloxacin tablet. Eur J Pharm Sci 2017; 101: 100-106.

12. Stillings $\mathrm{M}$ et al. Comparison of the pharmacokinetic profiles of soluble aspirin and solid paracetamol tablets in fed and fasted volunteers. Curr Med Res Opin 2000; 16: 115-124.
13. Rostami-Hodjegan A et al. A new rapidly absorbed paracetamol tablet containing sodium bicarbonate. I. A four-way crossover study to compare the concentration-time profile of paracetamol from the new paracetamol/sodium bicarbonate tablet and a conventional paracetamol tablet in fed. Drug Dev Ind Pharm 2002; 28: 523-531.

14. Souliman S et al. A level A in vitro/ in vivo correlation in fasted and fed states using different methods: applied to solid immediate release oral dosage form. Eur J Pharm Sci 2006; 27: 7279.

15. Greenblatt DJ et al. Comparison of pharmacokinetic profiles of zolpidem buffered sublingual tablet and zolpidem oral immediate-release tablet: results from a single-center, singledose, randomized, open-label crossover study in healthy adults. Clin Ther 2013; 35: 604-611.

16. Andreas CJ et al. Mechanistic investigation of the negative food effect of modified release zolpidem. Eur $J$ Pharm Sci 2017; 102: 284-298. 
17. Colo $S$ et al. Investigating the discriminatory power of BCS-biowaiver in vitro methodology to detect bioavailability differences between immediate release products containing a class I drug. Mol Pharm 2015; 12: 3167-3174.

18. Greenblatt DJ. Pharmacokinetic determinants of the clinical effects of benzodiazepine agonist hypnotics BT GABA and sleep: molecular, functional and clinical aspects. In: Monti JM et al., eds. Gaba and Sleep. Basel, Switzerland: Springer Basel, 2010: 95118.

19. Welling PG. Effects of food on drug absorption. Annu Rev Nutr 1996; 16: 383-415.

20. Gu CH et al. Predicting effect of food on extent of drug absorption based on physicochemical properties. Pharm Res 2007; 24: 1118-1130.

21. Rowland $\mathrm{M}$ et al. Physiologicallybased pharmacokinetics in drug development and regulatory science. Annu Rev Pharmacol Toxicol 2011; 51: 4573.

22. Shebley $\mathrm{M}$ et al. Physiologically based pharmacokinetic model qualification and reporting procedures for regulatory submissions: a consortium perspective. Clin Pharmacol Ther 2018; 104: 88-110.

23. Markopoulos C et al. In-vitro simulation of luminal conditions for evaluation of performance of oral drug products: choosing the appropriate test media. Eur J Pharm Biopharm 2015; 93: 173-182.

24. Darwich AS et al. Interplay of metabolism and transport in determining oral drug absorption and gut wall metabolism: a simulation assessment using the "Advanced Dissolution, Absorption, Metabolism (ADAM)" model. Curr Drug Metab 2010; 11: 716-729.

25. Jamei M et al. Population-based mechanistic prediction of oral drug absorption. AAPS J 2009; 11: 225-237.

26. Von Moltke LL et al. Zolpidem metabolism in vitro: responsible cytochromes, chemical inhibitors, and in vivo correlations. Br J Clin Pharmacol 1999; 48: 89-97.
27. Weinling $\mathrm{E}$ et al. Pharmacokinetic profile of a new modified release formulation of zolpidem designed to improve sleep maintenance. Fundam Clin Pharmacol 2006; 20: 397-403.

28. Obach RS et al. The prediction of human pharmacokinetic parameters from preclinical and in vitro metabolism data. J Pharmacol Exp Ther 1997; 283: 46-58.

29. Poulin P, Theil F-P. Development of a novel method for predicting human volume of distribution at steady-state of basic drugs and comparative assessment with existing methods. J Pharm Sci 2009; 98: 4941-4961.

30. Kaniwa $\mathrm{N}$ et al. Gastric emptying rates of drug preparations. II. Effects of size and density of enteric-coated drug preparations and food on gastric emptying rates in humans. J Pharmacobiodyn 1988; 11: 571-575.

31. Koziolek M et al. Simulating the postprandial stomach: physiological considerations for dissolution and release testing. Mol Pharm 2013; 10: 16101622.

32. Koziolek $\mathrm{M}$ et al. Intragastric volume changes after intake of a high-caloric, high-fat standard breakfast in healthy human subjects investigated by MRI. Mol Pharm 2014; 11: 16321639.

33. Olubodun JO et al. Pharmacokinetic properties of zolpidem in elderly and young adults: possible modulation by testosterone in men. Br J Clin Pharmacol 2003; 56: 297-304.

34. Greenblatt DJ et al. Influence of food on pharmacokinetics of zolpidem from fast dissolving sublingual zolpidem tartrate tablets. J Clin Pharmacol 2013; 53: 1194-1198.

35. Welling PG. Influence of food and diet on gastrointestinal drug absorption: a review. J Pharmacokinet Biopharm 1977; 5: 291-334.

36. Marathe $\mathrm{PH}$ et al. Evaluation of the effect of food on the pharmacokinetics of avitriptan. Biopharm Drug Dispos 1998; 19: 381-394.

37. Pao LH et al. Reduced systemic availability of an antiarrhythmic drug, bidisomide, with meal co-administration: relationship with region- dependent intestinal absorption. Pharm Res 1998; 15: 221-227.

38. Sunesen VH et al. Effect of liquid volume and food intake on the absolute bioavailability of danazol, a poorly soluble drug. Eur J Pharm Sci 2005; 24: 297-303.

39. Reppas C et al. Effect of hydroxypropylmethylcellulose on gastrointestinal transit and luminal viscosity in dogs. Gastroenterology 1991; 100: 1217-1223.

40. Parojči'c JP et al. Tablet disintegration and drug dissolution in viscous media: paracetamol IR tablets. Int $J$ Pharm 2008; 355: 93-99.

41. Levy G, Jusko WJ. Effect of viscosity on drug absorption. J Pharm Sci 1965; 54: 219-225.

42. Mudie DM et al. Physiological parameters for oral delivery and in vitro testing. Mol Pharm 2010; 7: 13881405.

43. Marciani L et al. Gastric response to increased meal viscosity assessed by echo-planar magnetic resonance imaging in humans. J Nutr 2000; 130: $122-$ 127.

44. Dikeman CL et al. Dietary fibers affect viscosity of solutions and simulated human gastric and small intestinal digesta. J Nutr 2006; 136: 913-919.

45. Takahashi T, Sakata T. Large particles increase viscosity and yield stress of pig cecal contents without changing basic viscoelastic properties. J Nutr 2002; 132: 1026-1030.

46. Goo RH et al. Circadian variation in gastric emptying of meals in humans. Gastroenterology 1987; 93: 515-518.

47. Davis SS et al. The effect of sleep on the gastrointestinal transit of pharmaceutical dosage forms. Int $\mathrm{J}$ Pharm 1992; 78: 69-76.

48. Ziessman HA et al. The added diagnostic value of liquid gastric emptying compared with solid emptying alone. J Nucl Med 2009; 50: 726-732.

49. Haase A et al. Gastrointestinal motility during sleep assessed by tracking of telemetric capsules combined with polysomnography - a pilot study. Clin Exp Gastroenterol 2015; 8: 327-332.

50. Treier $\mathrm{R}$ et al. Gastric motor function and emptying in the right decubitus 
and seated body position as assessed by magnetic resonance imaging. J Magn Reson Imaging 2006; 338: 331-338. https://doi.org/10.1002/jmri.20507.

51. Mojaverian $\mathrm{P}$ et al. Effects of gender, posture, and age on gastric residence time of an indigestible solid: pharmaceutical considerations. Pharm Res 1988; 5: 639-644.

52. Steingoetter A et al. Effects of posture on the physiology of gastric emptying : a magnetic resonance imaging study resonance imaging study. Scand J Gastroenterol 2006; 41: 1155-1164.
53. Hunt JN et al. The effect of gravity on gastric emptying with various test meals. J Physiol 1965; 178: 92-97.

54. Moore JG et al. Effect of body posture on radionuclide measurements of gastric emptying. Dig Dis Sci 1988; 33: 1592-1595.

55. Horowitz $\mathrm{M}$ et al. The effect of posture on gastric emptying and lntragastric distribution of oil and aqueous meal components and appetite. Gastroenterology 1993; 105: 382-390.

56. Salvà $\mathrm{P}$, Costa J. Clinical pharmacokinetics and pharmacodynamics of zolpidem. Therapeutic implications. Clin Pharmacokinet 1995; 29: 142-153.

57. Chetty $\mathrm{M}$ et al. Applications of linking PBPK and PD models to predict the impact of genotypic variability, formulation differences, differences in target binding capacity and target site drug concentrations on drug responses and variability. Front Pharmacol 2014; 5: 1-29.

58. Durand, et al. Comparative pharmacokinetic profile of two imidazo pyridine drugs: zolpidem and alpidem. Drug metab rev 1992; 24: 239-266. 